\title{
Incidence of primary cancers and intracranial tumour recurrences in GH-treated and untreated adult hypopituitary patients: analyses from the Hypopituitary Control and Complications Study
}

\author{
Christopher J Child, Daniel Conroy ${ }^{1}$, Alan G Zimmermann², \\ Whitney W Woodmansee ${ }^{3}$, Eva Marie Erfurth ${ }^{4}$ and Leslie L Robison ${ }^{5}$ \\ Lilly Research Laboratories, Erl Wood Manor, Windlesham, Surrey GU20 6PH, UK, 'inVentiv Health Clinical, \\ Burlington, Massachusetts 01803 USA, ${ }^{2}$ Lilly Research Laboratories, Indianapolis, Indiana 46285, USA, \\ ${ }^{3}$ Division of Endocrinology, Diabetes and Hypertension, Brigham and Women's Hospital/Harvard Medical School, \\ Boston, Massachusetts 02115, USA, ${ }^{4}$ Department of Endocrinology, Skånes University Hospital, Lund 221 85, \\ Sweden and ${ }^{5}$ Department of Epidemiology and Cancer Control, St Jude Children's Research Hospital, \\ Memphis, Tennessee 38105-3678, USA
}

\author{
Correspondence \\ should be addressed \\ to C J Child \\ Email \\ cjc@lilly.com
}

\begin{abstract}
Objective: Speculation remains that GH treatment is associated with increased neoplasia risk. Studies in GH-treated childhood cancer survivors suggested higher rates of second neoplasms, while cancer risk data for GH-treated and untreated hypopituitary adults have been variable. We present primary cancer risk data from the Hypopituitary Control and Complications Study (HypoCCS) with a focus on specific cancers, and assessment of recurrence rates for pituitary adenomas (PA) and craniopharyngiomas (CP).

Design: Incident neoplasms during HypoCCS were evaluated in $8418 \mathrm{GH}$-treated vs 1268 untreated patients for primary malignancies, $3668 \mathrm{GH}$-treated vs 720 untreated patients with PA history, and $956 \mathrm{GH}$-treated vs 102 untreated patients with CP history.

Methods: Using population cancer rates, standardised incidence ratios (SIRs) were calculated for all primary cancers, breast, prostate, and colorectal cancers. Neoplasm rates in $\mathrm{GH}$-treated vs untreated patients were analysed after propensity score adjustment of baseline treatment group imbalances.

Results: During mean follow-up of 4.8 years, 225 primary cancers were identified in GH-treated patients, with SIR of 0.82 (95\% Cl 0.71-0.93). SIRs ( $95 \% \mathrm{Cl})$ for GH-treated patients were $0.59(0.36-0.90)$ for breast, $0.80(0.57-1.10)$ for prostate, and $0.62(0.38-0.96)$ for colorectal cancers. Cancer risk was not statistically different between GH-treated and untreated patients (relative risk $(\mathrm{RR})=1.00(95 \% \mathrm{Cl} 0.70-1.41), P=0.98)$. Adjusted RR for recurrence was $0.91(0.68-1.22), P=0.53$ for $\mathrm{PA}$ and 1.32 (0.53-3.31), $P=0.55$ for $C P$.

Conclusions: There was no increased risk for all-site cancers: breast, prostate or colorectal primary cancers in GH-treated patients during HypoCCS. GH treatment did not increase the risk of PA and CP recurrences.




\section{Introduction}

Speculation remains that there may be an increased risk of neoplastic disease in growth hormone $(\mathrm{GH})$-treated patients $(1,2)$. The mitogenic and proliferative actions of GH and insulin-like growth factors (IGFs) have been demonstrated by epidemiological and experimental analyses $(3,4,5,6,7)$. In particular, epidemiological studies have shown an association between high levels of serum IGF1 and risk of developing certain malignancies, namely breast, prostate, and colorectal cancers $(8,9,10)$. Furthermore, patients with acromegaly, a condition caused by endogenous excess of GH and consequent increased levels of IGF1, have increased risk for development of, or mortality due to, colorectal cancer $(11,12,13)$.

Despite the associations shown in animal, in vitro, and clinical studies, increased risk for primary malignancy and neoplasm recurrence has not been confirmed in GH-treated patients. Data from an interim analysis of the Hypopituitary Control and Complications Study (HypoCCS) and a US-specific subset indicated no increased risk of primary cancers or recurrence of intracranial tumours in GH-treated adults, but were limited by a short period of follow-up and/or small number of patients $(14,15)$. Earlier retrospective studies of GH-treated cohorts in general had not indicated increased risk for malignancy $(16,17,18,19)$, although in the study of Swerdlow et al. (18) in patients treated with human cadaveric GH during childhood, the occurrence of colorectal cancer was significantly elevated vs general population rates. The majority of studies have shown GH replacement therapy in hypopituitary adults not to be associated with increased mortality due to malignancies $(19,20,21)$. However, in an epidemiological analysis of a Swedish subset of KIMS (Pfizer International Metabolic Database), excess mortality was found due to malignant brain tumours; notably of which, six of the affected eight patients had a benign pituitary tumour as primary disease and six of eight had received radiation therapy (22). Some studies of nonGH-treated hypopituitary patients have indicated increased cancer risk $(19,23,24)$, while others have not detected such a risk for malignancy (25).

The majority of studies in survivors of previous neoplasia, particularly brain tumours, have not indicated an association between GH treatment and increased tumour recurrence or occurrence of second neoplasms $(26,27,28,29,30,31)$. Two analyses from the Childhood Cancer Survivor Study (CCSS) indicated that GH treatment is associated with an increase in the relative risk (RR) of second neoplasms in childhood cancer survivors
$(32,33)$; these findings are supported by earlier analyses from HypoCCS (34). However, a recent follow-up report from this cohort of childhood cancer survivors did not show a significantly increased risk of secondary CNS tumours among long-term survivors who received GH-treatment during childhood (35).

This article presents a comprehensive assessment of the risk of primary cancer and recurrences of pituitary adenoma (PA) and craniopharyngioma (CP) in a large cohort of GH-treated and untreated adult hypopituitary patients who participated in the prospective, international HypoCCS observational study.

\section{Subjects and methods}

\section{Study design and study population}

The primary objective of HypoCCS was to determine long-term safety of GH replacement (Humatrope) in adults with GH deficiency (GHD) (36). All patients had established diagnoses of adult GHD, determined by clinical history and/or biochemical testing. As HypoCCS was a non-interventional study, the diagnostic approach and treatment decisions were determined by the investigating physician, but were governed by the Humatrope product label for that country. The patients were ineligible for HypoCCS if they had unresolved or unstable conditions listed as contraindications or precautions for GH therapy, including evidence or suspicion of active malignancy or evidence of ongoing pituitary or other intracranial tumour activity.

HypoCCS was conducted in accordance with the Declaration of Helsinki, all applicable regulatory requirements in the participating countries, and was registered with ClinicalTrials.gov, number NCT 01088399. Ethical review board approval and written patient consent for data collection, electronic processing, and publication were obtained in accordance with national laws.

Patients were recruited from Austria, Belgium, Canada, Czech Republic, Denmark, France, Germany, Hungary, Iceland, Italy, Japan, Norway, Slovakia, Spain, Sweden, The Netherlands, the UK, and the USA. Between 1996 and December 2012 (the end of study follow-up), the HypoCCS database included 9686 patients with at least one follow-up visit and had known therapy, age, and gender; 8418 were GH-treated during HypoCCS participation, 1268 were untreated (Fig. 1a) during the study. Of these, $3668 \mathrm{GH}$-treated and 720 untreated patients had 


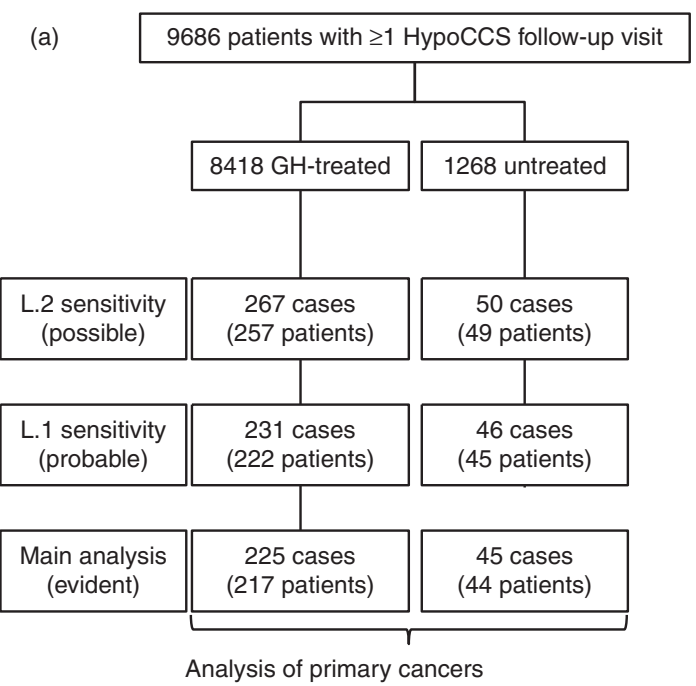

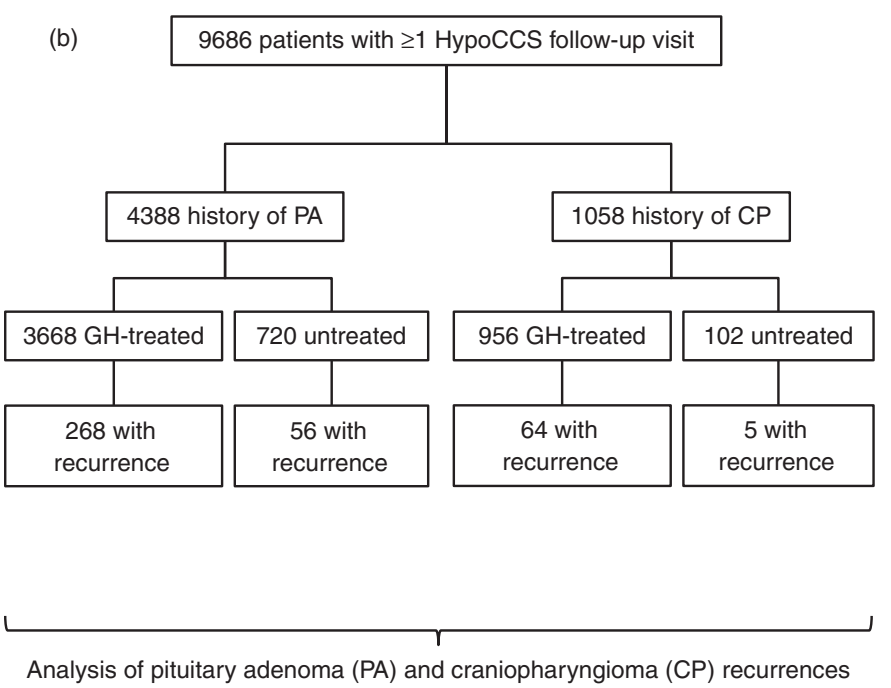

\section{Figure 1}

Deposition of adult hypopituitary patients reviewed for primary cancer (a) or pituitary adenoma (PA) and craniopharyngioma $(\mathrm{CP})$ recurrence $(\mathrm{b})$. Primary cancer cases were included in three

a history of PA, and 956 GH-treated and 102 untreated patients had a history of CP (Fig. 1b).

Follow-up time was calculated per patient from the date of first visit in HypoCCS until either the date of the last available follow-up visit, date of completion of the study, date of the reported neoplasm or date of death, whichever was the latest occurrence. It should be noted that first HypoCCS visit date may not reflect the exact start of GH treatment for an individual patient.

\section{Neoplasm history and incident case selection}

Preliminary review for potential cancer histories and cases - HypoCCS collected extensive data on aetiology of GHD including neoplasm-related causes of GHD, preexisting conditions and treatment-emergent adverse events, whether or not they were considered GH-related by participating investigators. All pre-existing conditions and adverse events in the database were coded using the Medical Dictionary for Regulatory Activities (MedDRA) version 14.0 (http://www.meddra.org/about-meddra/ vision, accessed 12 November 2014). As a first step, the HypoCCS database was systematically reviewed using the Malignancies Standardized MedDRA Query (SMQ) to select histories associated with neoplasms and incident events potentially related to malignant disease. The 'Malignancies SMQ' is a surveillance tool containing categories of events that only indicate the possibility of levels of analysis based on probability of being malignant: level 2 sensitivity (possible), level 1 sensitivity (probable), and main analysis (evident cancer cases).

cancer; thus, the preliminary listing contained many non-cancers and related conditions/therapies, as well as recurrences of previous malignancies. HypoCCS also collected information retrospectively on past history of cancer, diagnoses and prior therapies related to hypothalamic/pituitary disease, pre-existing multiple endocrine neoplasia and cancer and prospectively on new neoplastic conditions, using specific checkboxes on the case report forms. Such entries were reviewed to include any potential cases not reported as pre-existing conditions and adverse events, in particular to establish history of neoplasm. The neoplasm-related checkboxes included options for indicating recurrence of hypothalamic/pituitary tumour, benign neoplasm and malignant neoplasm. In situations where the only evidence of recurrence was the use of the checkbox, a case of recurrence was assumed based on the previous preHypoCCS history of disease. In addition, serious adverse event reports in the Lilly pharmacovigilance database were included if not already present in the preliminary listing.

Ascertainment of history of neoplasm and incident cancer cases $>$ Patients with history of neoplastic disease were identified from review of the varied data sources, with each specific neoplastic diagnosis assessed and flagged. Benign skin and vascular neoplasms including nevi, papillomas, angiomas and haemangiomas were excluded. Incident neoplasm cases with onset after the 
date of enrolment in HypoCCS were included in this analysis. Potential neoplasms were categorised as de novo, second and recurrence. De novo were defined as the first occurrence of neoplasm in a patient with no history of neoplasm, and second as development, by an independent oncogenic event, of a different neoplasm type in a patient with a previous neoplasm. Assignment of malignancy status was based on the methods described for the previous assessment of primary cancers in the HypoCCS database (14), with new cases not included previously, assigned the likelihood as being malignant based on the previous scheme. Three levels of likelihood of malignancy were assigned: i) 'evident cancer cases' for inclusion in the main analysis, ii) 'probable cancer cases' (e.g. certain unspecified tumours) for inclusion in level 1 sensitivity analyses (evident + probable cases) and iii) 'possible cancer cases' (e.g. non-specific event terms (such as mass, lesion, lump, tumour), procedures (such as elevated prostate-specific antigen, abnormal pap smear and breast biopsy) and investigations recorded without supporting information) for inclusion in level 2 sensitivity analyses (evident + probable + possible cases).

For the purposes of this analysis, recurrence included any recurrence, regrowth or increase in size of the preexisting tumour. When a patient had more than one recurrence during HypoCCS participation, only the first recurrence was counted for analysis, including the first during HypoCCS for any neoplasm that recurred before HypoCCS entry; recurrences of primary neoplasms first identified during HypoCCS participation were excluded.

\section{Descriptive statistics}

$P$ values for comparison of demographic parameters between GH-treated and untreated patients were calculated using the $\chi^{2}$ test for categorical variables and the $t$-test for continuous variables. The $P$ values were considered to be significant at a two-sided significance level of 0.05 .

\section{Standardised incidence ratio and $95 \% \mathrm{Cl}$ calculations for primary malignancies}

Standardised incidence ratios (SIRs) and corresponding 95\% CIs were calculated, by country, for primary all-site cancers: breast cancer, prostate cancer, and colorectal cancer, as the ratio between the number of cases observed in HypoCCS and the expected number of incident cases based on reference data. The expected case count was determined using gender-, race-, age-, and calendar yearspecific cancer incidence rates for the US general population from the Surveillance, Epidemiology and End Results (SEER) programme (37), and country-, gender-, and age-specific cancer incidence rates for the general population from GLOBOCAN data published by the International Agency for Research on Cancer (IARC) (38) for all other countries, applying the corresponding number of patient-years in HypoCCS. Total observed and expected counts per country were obtained by sum of the strata, and total SIR was estimated using the pooled results from all the participant countries. Although cases of potential breast cancer in men were reported in HypoCCS, only cases in women were included in SIR calculation as GLOBOCAN does not include male breast cancer rates. Patient years of follow-up for patients at risk for breast cancer and prostate cancer were adjusted to include women and men only respectively. Definition of cancer cases in HypoCCS was in accordance with SEER criteria (37), and therefore excluded non-melanoma skin cancer and in-situ cancers (except breast or bladder). Although in situ breast and bladder cancers are not included in the GLOBOCAN (38), they were included in these analyses to provide a conservative assessment.

The observed number of cancer cases was assumed to follow a Poisson distribution, and 95\% CI were calculated using an exact method (39).

\section{Comparison of neoplasm risk between GH-treated and untreated patients using propensity score adjustment}

Due to the observational nature of HypoCCS, adjustment for imbalances in patient characteristics between the GH-treated and untreated groups was made using stratified propensity score analysis (40) for assessment of the incidence of primary malignancies and recurrences of PA and CP. Propensity scores (the 'conditional probability of being treated') for all patients, those with history of PA and those with history of CP, were separately derived from a logistic regression model that included 27 covariates, selected either because of baseline imbalance between the HypoCCS treatment groups or their perceived impact on the occurrence of neoplasms. The list of covariates is provided in Supplementary Table 1, see section on supplementary data given at the end of this article. The patients were stratified into quintiles based on the propensity scores $(15,41)$; for primary malignancy and recurrent $\mathrm{PA}$, non-overlapping portions of the propensity score distributions were removed. Consequently, 70, 85, and $95 \%$ of baseline covariate comparisons showed no statistically significant treatment group differences after adjusting for propensity score quintiles for all patients, 
those with history of PA and those with history of CP respectively. Incidence rates of neoplasms of interest in GH-treated vs untreated patients were compared using the Cochran-Mantel-Haenszel method, controlling for the propensity score quintiles.

\section{Results}

\section{Demographics and follow-up}

Baseline demographic factors and GH treatment parameters are provided in Table 1 for all patients, those with history of PA and those with history of $\mathrm{CP}$, split by GH-treated and untreated patient groups. Among all enrolled patients, PA was the predominant cause of GHD, with CP as the second most common intracranial tumour leading to hypopituitarism. The proportion of patients who had $\geq 3$ pituitary hormone deficiencies in addition to GHD ranged from $\sim 50 \%$ (all patients, history of PA) to $80 \%$ (history of CP). The mean \pm s.D. follow-up/ patient for all patients was $4.8 \pm 3.9$ years for GH-treated and $3.5 \pm 2.4$ years for untreated patients, reflecting $\sim 40500$ and 4500 person-years of follow-up respectively. For patients with history of PA, mean follow-up was $5.2 \pm$ 4.0 (GH-treated) and 3.6 \pm 3.2 years (untreated), and for those with history of $\mathrm{CP}$, it was $5.1 \pm 4.0$ and $3.7 \pm 3.3$ years respectively.

\section{All-site primary cancer cases and risk}

For primary malignancies, 225 cases identified in 217 GH-treated patients and 45 cases in 44 untreated patients were included in the main analysis. Sensitivity analyses were performed to include cases not confirmed as cancer, with 267 cases in $257 \mathrm{GH}$-treated and 50 cases in 49 untreated patients in the sensitivity analyses (Fig. 1a). The most common primary cancer diagnoses from GH-treated patients in the main analysis were prostate cancers $(n=40)$; malignant melanomas $(n=22)$, including one case of lentigo maligna, breast cancers $(n=21)$; colorectal cancers $(n=20)$; lung cancers $(n=16)$; astroglial tumours $(n=14)$ and thyroid cancers $(n=13)$.

Table 1 Baseline demographics and GH treatment characteristics of all patients, patients with history of pituitary adenoma, and patients with history of craniopharyngioma.

\begin{tabular}{|c|c|c|c|c|c|c|c|c|c|}
\hline \multirow[b]{2}{*}{ Variable } & \multicolumn{3}{|c|}{ All patients } & \multicolumn{3}{|c|}{ History of pituitary adenoma } & \multicolumn{3}{|c|}{ History of craniopharyngioma } \\
\hline & GH-treated & Untreated & $P$ & GH-treated & Untreated & $P$ & GH-treated & Untreated & $P$ \\
\hline$n$ & 8418 & 1268 & - & 3668 & 720 & - & 956 & 102 & - \\
\hline Female $(\%)$ & 48 & 41 & $<0.0001$ & 43 & 37 & 0.0062 & 46 & 43 & 0.5374 \\
\hline Onset type (\% CO vs AO) & 20 vs 80 & 12 vs 88 & $<0.0001$ & 2 vs 98 & 1 vs 99 & 0.0280 & 38 vs 62 & 43 vs 57 & 0.2860 \\
\hline GH naïve vs GH non-naïve $(\%)^{a}$ & 74 vs 26 & 85 vs 15 & $<0.0001$ & 85 vs 15 & 93 vs 7 & $<0.0001$ & 64 vs 36 & 62 vs 38 & 0.6991 \\
\hline Cause of GHD $(\%)^{\mathrm{b}}$ & & & $<0.0001$ & & & 0.7282 & & & 0.7838 \\
\hline Pituitary adenomas & 43.4 & 56.5 & & 99.2 & 99.2 & & 0.4 & - & \\
\hline Craniopharyngiomas & 11.2 & 8.0 & & 0.1 & - & & 98.5 & 99.0 & \\
\hline Other intracranial tumours & 7.5 & 8.9 & & 0.3 & 0.3 & & 0.4 & - & \\
\hline Idiopathic GHD & 15.6 & 8.2 & & 0.0 & - & & - & - & \\
\hline Pituitary haemorrhage or infarct ${ }^{c}$ & 5.3 & 3.6 & & 0.1 & 0.1 & & - & - & \\
\hline Less common diagnoses ${ }^{d}$ & 11.8 & 9.2 & & 0.1 & 0.3 & & 0.2 & - & \\
\hline Other/unknown diagnoses & 5.2 & 5.7 & & 0.2 & 0.1 & & 0.4 & 1.0 & \\
\hline Hormone deficiencies $(\%)^{\mathrm{e}}$ & & & $<0.0001$ & & & 0.0449 & & & 0.0234 \\
\hline 0 & 17.0 & 13.2 & & 11.2 & 10.4 & & 2.2 & 2.0 & \\
\hline 1 & 16.9 & 18.2 & & 17.1 & 18.6 & & 4.4 & 3.9 & \\
\hline 2 & 17.6 & 20.7 & & 22.1 & 24.0 & & 7.0 & 11.8 & \\
\hline 3 & 33.0 & 37.5 & & 38.9 & 39.7 & & 26.6 & 38.2 & \\
\hline 4 & 15.4 & 10.4 & & 10.8 & 7.2 & & 59.8 & 44.1 & \\
\hline Mean baseline age (year) & 45.5 & 53.8 & $<0.0001$ & 51.6 & 58.8 & $<0.0001$ & 37.5 & 43.0 & 0.0002 \\
\hline Mean GH dose ( $\mu \mathrm{g} /$ day) & 356.2 & NA & NA & 354.3 & NA & NA & 354.8 & NA & NA \\
\hline Mean follow-up (year) & 4.8 & 3.5 & $<0.0001$ & 5.2 & 3.6 & $<0.0001$ & 5.1 & 3.7 & 0.0001 \\
\hline Person-years of follow-up & 40575 & 4476 & $<0.0001$ & 18890 & 2592 & $<0.0001$ & 4837 & 377 & $<0.0001$ \\
\hline
\end{tabular}

AO, adult-onset GHD; CO, childhood-onset GHD; GH, growth hormone; GHD, growth hormone deficiency; HypoCCS, Hypopituitary Control and Complications Study; NA, not applicable.

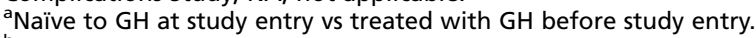

b Data as reported by site from the HypoCCS diagnostic module; history of pituitary adenoma or craniopharyngioma may have been based on other data sources such as pre-existing conditions.

Including trauma and Sheehan syndrome.

dIncluding sarcoidosis, empty sella, hypophysitis, pituitary infection, known and unknown genetic defects and cranial irradiation.

e In addition to GHD. 
The overall estimated SIR for evident cases (main analysis) in GH-treated patients was 0.82 (95\% CI 0.71-0.93) and for the USA, which contributed roughly half of the enrolled patients, was 0.85 (95\% CI 0.69-1.04). Case counts and SIRs for all primary invasive cancers in HypoCCS are given by country in Table 2 when the observed case count per country is at least ten; Japan was the only individual country to have a significantly elevated SIR (2.33 (95\% CI 1.20-4.06)). Inclusion of cases in GH-treated patients where malignancy status could not be clarified increased the number of observed cases from 225 to 231 (level 1 sensitivity, including probable cases) and 267 (level 2 sensitivity, including possible cases), giving SIRs of 0.84 (95\% CI $0.73-0.95)$ and 0.97 (0.86-1.09), respectively, for all countries combined, and 0.97 (95\% CI 0.79-1.17) and 1.22 (1.02-1.45), respectively, for patients from the USA. The 42 cases added for the sensitivity analyses across all countries included event terms of breast biopsy/lump/mass/neoplasm (seven cases), elevated prostate-specific antigen/prostate nodule (six cases), lung lesion/neoplasm/nodule (five cases), abnormal pap smear (five cases), renal tumour/mass/ nephrectomy (five cases), unspecified skin cancer (three cases) and unspecified brain lesions (two cases).

Of the 225 cancer cases included in the main analysis, 147 were in men and 78 were in women. For all countries, there were 205 cancer cases in 6732 patients with adult onset (AO) GHD (SIR $0.78(0.68-0.90)$ ) and 20 cases in 1642 patients with childhood-onset (CO) GHD (SIR 1.0 (0.61-1.54)). When considering cases for the USA alone, the SIR for cancers in CO patients rose to 2.08 (0.95-3.95).

Table 2 Standardised incidence ratios (SIRs) for evident primary cancers (all sites), by country and total, in GH-treated patients.

\begin{tabular}{|c|c|c|c|c|}
\hline Country $^{a}$ & $n$ & $\begin{array}{c}\text { Observed } \\
\text { cases }\end{array}$ & $\begin{array}{l}\text { Expected } \\
\text { cases }\end{array}$ & SIR $(95 \% \mathrm{CI})$ \\
\hline France & 447 & 10 & 12.06 & $0.83(0.40-1.52)$ \\
\hline Germany & 530 & 11 & 19.06 & $0.58(0.29-1.03)$ \\
\hline Italy & 1152 & 16 & 31.88 & $0.50(0.29-0.82)$ \\
\hline Japan & 402 & 12 & 5.16 & $2.33(1.20-4.06)$ \\
\hline Sweden & 351 & 15 & 24.09 & $0.62(0.35-1.03)$ \\
\hline The Netherlands & 457 & 19 & 24.24 & $0.78(0.47-1.22)$ \\
\hline UK & 524 & 14 & 18.77 & $0.75(0.41-1.25)$ \\
\hline $\mathrm{USA}^{\mathrm{b}}$ & 3599 & 99 & 115.84 & $0.85(0.69-1.04)$ \\
\hline Total $^{\mathrm{b}}$ & 8418 & 225 & 275.83 & $0.82(0.71-0.93)$ \\
\hline
\end{tabular}

SIR, standardised incidence ratio; SEER, Surveillance, Epidemiology and End Results (programme).

${ }^{a}$ Countries with $\leq 10$ observed cases are not listed but are included in the total (Austria, 3 cases; Belgium, 1; Canada, 0; Czech Republic, 5; Denmark, 9; Hungary, 1; Iceland, 1; Norway, 0 and Spain, 9).

bUses SEER (1992-2010) data for USA; all other countries used GLOBOCAN 2008.
There was a significantly higher SIR for patients in the lowest age quartile ( $<34.95$ years of age), but not in any other age quartile $(34.95$ to $<47.55,47.55$ to $<57.91$, or $\geq 57.91$ years of age). The SIRs for patients $<34.95$ years of age were 4.45 (2.22-7.96) for the USA, 2.04 (1.11-3.42) for all other countries and 2.68 (1.73-3.97) for all countries combined, based on 11, 14 and 25 observed and 2.47, 6.86 and 9.33 expected cancer cases respectively. Of the 217 GH-treated patients with cancer cases included in the main analysis, 28 had a report of previous malignant disease. Twelve of the previous primary cancers were intracranial tumours (astroglial, medulloblastoma or germ cell cancer) or leukaemia, of the types often occurring during childhood, reflected in 10 (83\%) having CO GHD and the mean age at onset of the second cancer being $32.6 \pm 10.7$ years. The remaining 16 patients, with average age of $64.2 \pm 20.4$ years at onset of second cancer and 15 (94\%) having AO GHD, had primary cancers more typically associated with adulthood, including seven patients with skin cancers; three patients with nasal/ nasopharyngeal cancers; and single cases of breast, cervical, lung and thyroid cancers, plus haemangiopericytoma and a patient with history of potentially malignant multiple endocrine neoplasia. The 28 second cancers observed during HypoCCS participation included seven skin/soft tissue cancers, five glial tumours, four lung cancers, two thyroid cancers, and two uterine cancers as well as single cases of a variety of cancer types and sites.

As the impact of exposure to $\mathrm{GH}$ before HypoCCS entry cannot be precisely determined in terms of contribution to the number of incident cases or patientyears of exposure, analyses were repeated for those patients considered naïve to $\mathrm{GH}$ at study entry. For all countries combined, the all-site primary cancers SIR for GH-treated patients who were GH-naïve at study entry was 0.87 (0.76-1.00) based on 206 observed cases and an expected count of 235.88 vs the SIR of 0.82 (95\% CI 0.71-0.93) for all GH-treated patients. The SIR for all-site primary cancers in untreated patients was $0.86(0.63-1.15)$ based on 45 observed cases among the 1268 untreated patients from all participating countries (Table 3). For the USA alone, which contributed 773 (61\%) of the untreated patients, the SIR for untreated patients was 0.99 (0.69-1.37) based on 36 observed cases.

\section{Primary breast, prostate, and colorectal cancer cases and risk}

Twenty-three evident breast cancers in female patients were observed in the overall HypoCCS population (21 in 
Table 3 Standardised incidence ratios (SIRs) for all sites: breast, prostate, and colorectal cancers in GH-treated and untreated patients (all countries).

\begin{tabular}{lllr}
\hline Type & & Treatment & N \\
\cline { 1 - 1 } All sites & GH-treated & 8418 \\
Breast (female only ${ }^{\mathrm{a}}$ ) & Untreated & 1268 \\
& GH-treated & 4024 \\
Prostate (male only) & Untreated & 523 \\
Colorectal & GH-treated & 4394 \\
& Untreated & 745 \\
& GH-treated & 8418 \\
\hline
\end{tabular}

\begin{tabular}{c}
\hline Observed \\
\hline 225 \\
45 \\
21 \\
2 \\
40 \\
12 \\
20 \\
8 \\
\hline
\end{tabular}

\begin{tabular}{c}
\hline Expected \\
\hline 275.83 \\
52.11 \\
35.79 \\
4.33 \\
49.72 \\
12.16 \\
32.11 \\
5.84 \\
\hline
\end{tabular}

\begin{tabular}{c} 
SIR (95\% CI) \\
\hline $0.82(0.71-0.93)$ \\
$0.86(0.63-1.15)$ \\
$0.59(0.36-0.90)$ \\
$0.46(0.06-1.67)$ \\
$0.80(0.57-1.10)$ \\
$0.99(0.51-1.72)$ \\
$0.62(0.38-0.96)$ \\
$1.37(0.59-2.70)$ \\
\hline
\end{tabular}

SIR, standardised incidence ratio; GH, growth hormone.

${ }^{a}$ Analysis was performed on the female-only study population as no expected male breast cancer rate was available from GLOBOCAN; one case of evident breast cancer and one level 2 sensitivity case were identified in male patients.

the GH-treated group and two in the untreated group), giving estimated SIRs for breast cancer in GH-treated female patients of $0.59(0.36-0.90)$ vs 0.46 (0.06-1.67) for untreated patients (Table 3). In male patients only, 52 cases of evident prostate cancer were reported, with 40 in GH-treated patients (SIR 0.80 (0.57-1.10)) and 12 in the untreated patients (SIR 0.99 (0.51-1.72)). For colorectal cancers, a total of 28 cases were reported, with 20 in GH-treated patients (SIR 0.62 (0.38-0.96)) and eight in the untreated patients (SIR 1.37 (0.59-2.70)). All breast cancers and all prostate cancers in GH-treated patients were reported in patients with $\mathrm{AO}$ GHD. Likewise, all colorectal cancers in GH-treated patients were reported in patients with AO GHD, with 14 of the cases in men (SIR $0.65(0.36-1.10)$ ) vs six cases in women (SIR $0.56(0.21-1.22))$.

\section{Comparison between GH-treated and untreated patients for incidence of primary cancer and recurrences of PA and CP}

After adjustment for imbalances in 27 selected baseline variables using the propensity score method, no significant difference was observed in the incidence of primary malignancies between $\mathrm{GH}$-treated and untreated patients (RR (95\% CI) of 1.00 (0.70-1.41), $P=0.98$ ) (Table 4).

The majority of patients enrolled in the HypoCCS programme were hypopituitary as a result of intracranial tumour (Table 1). For PA, the most common cause of hypopituitarism in the database, 268 of 3668 (7.3\%) GH-treated patients suffered tumour recurrence, while 56 of $720(7.8 \%)$ untreated patients had a recurrence. CP recurrence was reported for 64 of 956 (6.7\%) GH-treated patients and five of 102 (4.9\%) untreated HypoCCS patients (Fig. 1b). Crude incidence (95\% CI) rates of PA and CP recurrences in GH-treated patients were 14.2 (12.616.0) per 1000 person-years and 13.2 (10.2-16.9) per 1000 person-years respectively. No significant differences were observed in the incidence of these typically benign intracranial tumours between GH-treated and untreated patients after adjustment for baseline imbalances; RR for PA recurrence was $0.91(0.68-1.22), P=0.53$, while for $\mathrm{CP}$ there was a higher rate of recurrence in the $\mathrm{GH}$-treated patients, but without statistical significance (- RR $1.32(0.53-3.31)$, $P=0.55$ ) (Table 4).

Table 4 Relative risk for neoplasm outcomes in GH-treated vs untreated patients after propensity score adjustment.

\begin{tabular}{l} 
Outcome measure \\
\hline Primary malignancy \\
Pituitary adenoma \\
recurrence \\
Craniopharyngioma \\
recurrence
\end{tabular}

\begin{tabular}{c}
\hline GH-treated $\boldsymbol{n} / \mathbf{N}(\%)$ \\
\hline $217 / 8410(2.6)$ \\
$257 / 3537(7.3)$ \\
$64 / 956(6.7)$
\end{tabular}

\begin{tabular}{c}
\hline Untreated $\boldsymbol{n} / \mathbf{N}(\%)$ \\
\hline $44 / 1265(3.5)$ \\
$56 / 720(7.8)$
\end{tabular}

$\frac{\text { Total } \boldsymbol{n} / \boldsymbol{N}(\%)}{261 / 9675(2.7)}$

P value $\chi^{2 a}$
0.07

\begin{tabular}{c}
$\boldsymbol{P}$ value $\mathbf{C M H}^{\mathrm{b}}$ \\
\hline 0.98 \\
0.53
\end{tabular}

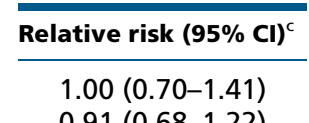

$5 / 102(4.9)$

$69 / 1058(6.5)$

0.49

0.55

$0.91(0.68-1.22)$

$\mathrm{CMH}$, Cochran-Mantel-Haenszel; GH, growth hormone.

${ }^{a} P$ value from the contingency table without adjusting for propensity scores.

${ }^{\mathrm{b}} P$ value from the stratified contingency table adjusting for propensity score quintile.

${ }^{\mathrm{C}}$ Relative risk was calculated using Mantel-Haenszel.

${ }^{\mathrm{d}}$ Non-overlapping portions of the propensity score distributions have been removed. 


\section{Discussion}

The primary objective of the HypoCCS programme was stated as to determine whether long-term GH replacement therapy administered in clinical practice to adults with GHD is associated with increased or decreased incidences of clinically significant adverse events'. As concerns have remained that GH treatment may be associated with increased cancer risk since GH replacement in adult hypopituitary patients was first approved in 1995 (1), detailed analysis of neoplasia risk is of critical importance. Initial analysis on incidence of primary cancer from this database indicated no increased risk for primary cancers in GH-treated adult hypopituitary patients in HypoCCS (14). At study close, and with an increment to over 40500 person-years for GH-treated and 4476 for untreated patients, compared with 25034 and 2688, respectively, in the previous analysis, there remained no evidence of increased risk for primary cancers in GH-treated adult patients across all countries when comparing with general population cancer rates. One country, Japan, had a significantly elevated SIR for all-site cancers, based on 12 observed cases (in 11 patients) and 5.2 expected cases based on general population data. HypoCCS was initiated later in Japan (April 2006) than in the majority of participant countries. Details of all of the Japanese patients have been described previously (42); four of the ten patients had received GH treatment for $<1$ year, and one had received cranial irradiation that was strongly suspected to be the cause of the glioblastoma. One Japanese patient, described in that publication with unknown malignancy status, had reported onset of germinoma 0.6 years after initiation of GH therapy for GHD caused by autoimmune hypophysitis; cases of hypophysitis preceding or masking diagnosis of germinoma have been described (43).

Sensitivity analyses that incorporated cases of uncertain malignant status were performed for all-site cancers. The SIR for all countries combined was not significantly elevated upon inclusion of these additional cases. In addition to Japan, the SIR was only elevated for one additional country - a small SIR increase for the USA at the level 2 sensitivity analysis. It is unlikely that this data represent a clinically significant finding because unconfirmed cases will not be recorded in the comparator registries and the SIR increase was small. In addition to the approach comparing incidence in HypoCCS with general population comparator rates, rates of all-site primary cancer in GH-treated vs untreated HypoCCS patients were directly compared after adjustment for baseline treatment group imbalances using propensity score methodology. No significant difference in the rate of primary malignancies between GH-treated and untreated patients was observed.

Analysis of cancer incidence by age quartiles indicated an increased risk for the youngest quartile of patients (those $<34.95$ years of age); for all countries combined this was based on 9.33 expected and 25 observed cases. Additionally, the SIR for primary cancers in US patients with CO GHD was significantly elevated. As reported previously from the HypoCCS database it is reasonable to conclude that a proportion of these patients have a higher risk of second neoplasms associated with survival of childhood neoplastic disease $(14,34)$. The updated analysis presented here included 28 patients with history of malignancy prior to HypoCCS entry, including 12 with history of intracranial tumours or leukaemia and mean age at second cancer onset of 32.6 years, and ten of whom had CO GHD. Data from the SEER programme indicated a sixfold increased risk of subsequent malignancy in childhood cancer survivors compared with the general population (44). Analyses of the CCSS indicated that GH-treated cancer survivors treated have increased risk for development of second neoplasms compared with untreated patients (32) but with diminishing risk with increasing duration of follow-up (33). However, the recent update from the CCSS on subsequent CNS neoplasms (meningioma and glioma), has indicated that there was no statistically significant increased overall risk of the occurrence of a CNS-second neoplasm associated with GH exposure (35).

An association has been suggested between high serum IGF1 concentrations and breast, prostate, and colorectal cancers $(5,45)$. An increased risk for colorectal cancer (SIR 7.9 (95\% CI 1.0-28.7)) was reported in one study that followed-up on CO GHD adults previously treated with pituitary derived GH during childhood or early adulthood (18). Although the findings were based on two observed cases vs a very small expected count and with regimens not directly related to biosynthetic GH usage, further evaluation of colorectal cancer in contemporary cohorts was justified. The increased patient number and extended follow-up in this report allowed for analysis by site-specific tumour type. Acknowledging a mean follow-up of only 4.8 years, the SIRs for the separate specific analyses of breast, prostate and colorectal cancers in GH-treated patients were all below unity $(0.62(0.38-0.96), 0.59$ (0.36-0.90), and $0.80(0.57-1.10)$, respectively). All cases of breast, prostate, and colorectal cancers reported in HypoCCS were in patients with AO GHD. 
PA and/or its treatment was the predominant cause of GHD in the HypoCCS cohort, with sequelae of CP the second most prevalent intracranial tumour cause of GHD. The proportion of patients suffering recurrence of PA and $\mathrm{CP}$ in a previous analysis of a US subset of the HypoCCS cohort was $2.5 \%$ (GH-treated) and $4.4 \%$ (untreated), and $3.8 \%$ (GH-treated) and 5.6\% (untreated), respectively, with no statistical significance between the treatment groups (15). In this analysis of the final complete HypoCCS dataset, the proportion of patients with recurrence was in general somewhat higher than the previous assessment (for PA: $7.3 \%$ of GH-treated and $7.8 \%$ untreated, and for CP: $6.7 \%$ GH-treated and $4.9 \%$ untreated), but critically, again, there was no observed statistically significant difference in recurrence rates between GH-treated and untreated patients. Reasons for the higher rates of observed recurrence in this later analysis may include longer follow-up time and differences in ascertainment. The incidences of recurrence observed in HypoCCS were consistent with those observed in other surveillance studies and retrospective cohort studies from single or multiple investigative centres for adult patients with GHD. From their single-centre study, Hatrick et al. (46) reported two cases (4.3\%) of recurrence of PA in 47 patients treated for a mean of 3.6 years, and two (7.1\%) in 28 untreated control patients with a mean of 3.4 years between imaging studies. The rate of recurrence of PA in HypoCCS was, however, much lower than the rates of recurrence of non-functioning PA observed in the KIMS surveillance programme. In an analysis of $55 \mathrm{GH}$-matched pairs for GH-treatment and non-treatment within a follow-up period of 5 years, there were recurrence rates of 29.1 and $21.8 \%$ respectively, but with no statistical difference between the treatment groups (47). In their series of 85 patients with a history of CP and follow-up imaging, Karavitaki et al. (28) observed four $(12.5 \%)$ cases of recurrence in 32 patients treated with GH for a mean of 6.3 years and mean follow-up of 10.8 years, and $22(41.5 \%)$ in 53 untreated patients with mean duration of follow-up of 8.3 years. After adjusting for sex, age at tumour diagnosis, and type of tumour therapy, GH treatment was not a significant independent predictor of recurrence $(P=0.06$; hazard ratio $=0.309)$. In a more recently published evaluation of risk of $\mathrm{CP}$ recurrence in 56 GH-treated adult patients with long-term GH exposure of mean 13.6 years vs that in 70 untreated controls, after adjustment for initial radiation therapy, presence of residual tumour (postsurgery), and gender, the 10-year progression-free survival rate was $85 \%$ for the GH-treated group and $65 \%$ for the untreated group (48).
These results on primary all-site and site-specific cancers, and recurrences of PA and CP, appear reassuring, especially as deliberately liberal approaches were taken towards case ascertainment. However, there are a number of limitations of these analyses. SIRs for all-site cancers and the site-specific cancers of interest are all well below 1.0 for GH-treated patients and so would appear to indicate lower risk for primary cancer than in the general population. Possible factors may include relatively healthier hypopituitary patients and/or those with higher socioeconomic status being more likely to be selected to receive GH replacement and/or more likely to agree to study participation. It should be noted that direct comparison of rates of all-site primary cancer between GH-treated and untreated groups in HypoCCS (adjusted for propensity score) resulted in RR of 1.00. Despite extended person years of follow-up, the average time of follow-up in HypoCCS remains relatively short (mean 4.8 years for all GH-treated patients). However, the SIRs for both $\mathrm{GH}$-treated and untreated patients have reduced with increased follow-up since the previous analysis, from 0.88 (0.74-1.04) previously (14) to $0.82(0.71-0.93)$ for GH-treated patients in this report. Cancer/tumour induction time was not used to adjust our analyses. Although cancer risk appeared to drop with a modest increment in average follow-up, there is the possibility that a higher risk for neoplastic disease might be revealed with longer GH treatment and/or follow-up. However, it can also be argued that cases diagnosed soon after GH initiation for GH-naïve patients in HypoCCS were unlikely due to GH treatment, leading to overestimation of observed cases. Because follow-up time accrual was only that during HypoCCS participation, no extra time would have been added to the patient-years calculation for a patient treated with GH prior to HypoCCS. Approximately one-quarter of patients treated with GH during the study had received GH treatment, predominantly during childhood, prior to study entry. The impact of such previous GH treatment on cancer risk cannot be directly determined. However, the finding of a similar SIR $(95 \% \mathrm{CI})$ for patients naïve to $\mathrm{GH}$ at study entry (0.87 (0.76-1.00)) compared to the overall SIR (95\% CI) (0.82 (0.71-0.93)) mitigates concerns regarding inclusion of previously treated patients to a certain extent. The HypoCCS programme followed patients from 1996 to 2012 and during this time there have been changes in clinical practice and aetiology of GHD with a relative decrease in the proportion of intracranial tumours and pituitary dysfunction diagnoses (36). GH-treated patients were somewhat younger than the untreated patients at baseline, had a higher rate of idiopathic GHD diagnosis 
and a lower rate of PA (Table 1). Such differences may have an influence on the comparative risk for primary malignancy between treatment groups based on general population data, but were largely mitigated when comparing primary cancer risk in the GH-treated and untreated patients after propensity score adjustment. Risk for primary cancer appears higher in the lowest age quartile of our analysis and previous radiotherapy for childhood cancer is likely to be an important factor in the increased cancer incidence in the lowest age group. The HypoCCS database was limited in this respect regarding collection of data on history, type, and quantity of radiotherapy; such that specific analyses to assess the risk for radiationassociated cancer morbidity were not possible. Finally, the propensity score method cannot control for unmeasured differences between the treatment groups (e.g. socioeconomic factors, which may influence cancer risk). The use of two distinct statistical methods to evaluate cancer incidence mitigates some of the limitations of the individual methods utilised to analyse this observational data.

In conclusion, GH-replaced adult patients in HypoCCS did not appear to have an increased risk for all-site primary cancer during study, whether compared with the general population of the HypoCCS cohort or untreated patients with adult GHD. Similarly there was no apparent elevated risk for breast, prostate, or colorectal cancers in GH-treated HypoCCS patients in comparison with general population data. Finally, no significant differences in the recurrence rates for $\mathrm{PA}$ or $\mathrm{CP}$ between GH-treated and untreated hypopituitary patients were observed.

Supplementary data

This is linked to the online version of the paper at http://dx.doi.org/10.1530/ EJE-14-1123.

\section{Declaration of interest}

C J Child and A G Zimmermann are employees and stockholders of Eli Lilly and Company (Indianapolis, IN, USA). E M Erfurth, L L Robison, and W W Woodmansee have been members of Medical Research advisory boards for and have received consulting fees from Eli Lilly and Company. W W Woodmansee is also a former employee and stockholder of Eli Lilly and Company. D Conroy is employed by inVentiv Health Clinical that has received payments from Eli Lilly and Company for statistical services connected with this project.

\section{Funding}

HypoCCS was sponsored by Eli Lilly and Company (Indianapolis, IN, USA). In compliance with the Uniform Requirements for Manuscripts, established by the International Committee of Medical Journal Editors, the sponsor of this study did not impose any impediment, directly or indirectly, on the publication of the study's results.

\section{Acknowledgements}

The authors express their grateful thanks to all the participant patients, investigators, study coordinators, and numerous Lilly employees for their dedication to the study. In addition, they thank the members of the International HypoCCS Advisory Board who provided scientific guidance over the period of the study.

\section{References}

1 Pekic S \& Popovic V. GH therapy and cancer risk in hypopituitarism: what we know from human studies. European Journal of Endocrinology 2013169 R89-R97. (doi:10.1530/EJE-13-0389)

2 Deodati A, Ferroli BB \& Cianfarani S. Association between growth hormone therapy and mortality, cancer and cardiovascular risk: systemic review and meta-analysis. Growth Hormone \& IGF Research 201424 105-111. (doi:10.1016/j.ghir.2014.02.001)

3 Pollak MN, Schernhammer ES \& Hankinson SE. Insulin-like growth factors and neoplasia. Nature Reviews. Cancer 20044 505-518. (doi:10.1038/nrc1387)

4 Popovic V, Mattsson AF, Gaillard RC, Wilton P, Koltowska-Häggstöm M \& Ranke MB. Serum insulin-like growth factor I (IGF-I), IGF-binding proteins 2 and 3, and the risk for development of malignancies in adults with growth hormone (GH) deficiency treated with $\mathrm{GH}$ : data from KIMS (Pfizer International Metabolic Database). Journal of Clinical Endocrinology and Metabolism 201095 4449-4454. (doi:10.1210/jc. 2010-0287)

5 Renehan AG, Zwahlen M, Minder C, O'Dwyer ST, Shalet SM \& Egger M Insulin-like growth factor (IGF)-I, IGF binding protein-3, and cancer risk: systematic review and meta-regression analysis. Lancet 2004363 1346-1353. (doi:10.1016/S0140-6736(04)16044-3)

6 Samani AA, Yakar S, LeRoith D \& Brodt P. The role of the IGF system in cancer growth and metastasis: overview and recent insights. Endocrine Reviews 200728 20-47. (doi:10.1210/er.2006-0001)

7 Seccareccia E \& Brodt P. The role of the insulin-like growth factor-I receptor in malignancy: an update. Growth Hormone \& IGF Research 201222 193-199. (doi:10.1016/j.ghir.2012.09.003)

8 Chan JM, Stampfer MJ, Giovannucci E, Gann PH, Ma J, Wilkinson P, Hennekens $\mathrm{CH} \&$ Pollak M. Plasma insulin-like growth factor-I and prostate cancer risk: a prospective study. Science 1998279 563-566. (doi:10.1126/science.279.5350.563)

9 Ma J, Pollak MN, Giovannucci E, Chan JM, Tao Y, Hennekens CH \& Stampfer MJ. Prospective study of colorectal cancer risk in men and plasma levels of insulin-like growth factor (IGF)-I and IGF-binding protein-3. Journal of the National Cancer Institute 199991 620-625. (doi:10.1093/jnci/91.7.620)

10 Endogenous Hormones and Breast Cancer Collaborative Group, Key TJ, Appleby PN, Reeves GK \& Roddam AW. Insulin-like growth factor 1 (IGF1), IGF binding protein 3 (IGFBP3), and breast cancer risk: pooled individual data analysis of 17 prospective studies. Lancet. Oncology 2010 11 530-542. (doi:10.1016/S1470-2045(10)70095-4)

11 Jenkins PJ, Fairclough PD, Richards T, Lowe DG, Monson J, Grossman A, Wass JA \& Besser M. Acromegaly, colonic polyps and carcinoma. Clinical Endocrinology 199747 17-22. (doi:10.1046/j. 1365-2265.1997.1911029.x)

12 Orme SM, McNally RJ, Cartwright RA \& Belchetz PE. Mortality and cancer incidence in acromegaly: a retrospective cohort study, United Kingdom Acromegaly Study Group. Journal of Clinical Endocrinology and Metabolism 199883 2730-2734. (doi:10.1210/jcem.83.8.5007) 
13 Melmed S, Casanueva FF, Klibanski A, Bronstein MD, Chanson P, Lamberts SW, Strasburger CJ, Wass JA \& Giustina A. A consensus on the diagnosis and treatment of acromegaly complications. Pituitary 2013 16 294-302. (doi:10.1007/s11102-012-0420-x)

14 Child CJ, Zimmermann AG, Woodmansee WW, Green DM, Li JJ, Jung H, Erfurth EM, Robison LL \& HypoCCS International Advisory Board. Assessment of primary cancers in GH-treated adult hypopituitary patients: an analysis from the Hypopituitary Control and Complications Study. European Journal of Endocrinology 2011165 217-223. (doi:10.1530/EJE-11-0286)

15 Hartman ML, Xu R, Crowe BJ, Robison LL, Erfurth EM, Kleinberg DL, Zimmermann AG, Woodmansee WW, Cutler GB Jr, Chipman JJ et al. Prospective safety surveillance of GH-deficient adults: comparison of GH-treated vs untreated patients. Journal of Clinical Endocrinology and Metabolism 201398 980-988. (doi:10.1210/jc.2012-2684)

16 Monson JP. Long-term experience with GH replacement therapy: efficacy and safety. European Journal of Endocrinology 2003148 (Suppl 2) S9-S14. (doi:10.1530/eje.0.148S009)

17 Mills JL, Schonberger LB, Wysowski DK, Brown P, Durako SJ, Cox C, Kong F \& Fradkin JE. Long-term mortality in the United States cohort of pituitary-derived growth hormone recipients. Journal of Pediatrics 2004 144 430-436. (doi:10.1016/j.jpeds.2003.12.036)

18 Swerdlow AJ, Higgins CD, Adlard P \& Preece MA. Risk of cancer in patients treated with human pituitary growth hormone in the UK, 1959-85: a cohort study. Lancet 2002360 273-277. (doi:10.1016/ S0140-6736(02)09519-3)

19 Svensson J, Bengtsson BA, Rosén T, Odén A \& Johannsson G. Malignant disease and cardiovascular morbidity in hypopituitary adults with or without growth hormone replacement therapy. Journal of Clinical Endocrinology and Metabolism 200489 3306-3312. (doi:10.1210/jc. 2003-031601)

20 van Bunderen CC, van Nieuwpoort IC, Arwert LI, Heymans MW, Franken AA, Koppeschaar HP, van der Lely AJ \& Drent ML. Does growth hormone replacement therapy reduce mortality in adults with growth hormone deficiency? Data from the Dutch National Registry of Growth Hormone Treatment in adults. Journal of Clinical Endocrinology and Metabolism 201196 3151-3159. (doi:10.1210/jc.2011-1215)

21 Gaillard RC, Mattsson AF, Akerblad AC, Bengtsson A, Cara J, FeldtRasmussen U, Koltowska-Häggström M, Monson JP, Saller B, Wilton P $\&$ Abs R. Overall and cause-specific mortality in GH-deficient adults on GH replacement. European Journal of Endocrinology 2012166 1069-1077. (doi:10.1530/EJE-11-1028)

22 Burman P, Mattsson AF, Johannsson G, Höybye C, Holmer H, Dahlqvist P, Berinder K, Engström BE, Ekman D, Erfurth EM et al. Deaths among adult patients with hypopituitarism: hypocortisolism during acute stress, and de novo malignant brain tumors contribute to an increased mortality. Journal of Clinical Endocrinology and Metabolism 201398 1466-1475. (doi:10.1210/jc.2012-4059)

23 Popovic V, Damjanovic S, Micic D, Nesovic M, Djurovic M, Petakov M, Obradovic S, Zoric S, Simic M, Penezic Z et al. Increased incidence of neoplasia in patients with pituitary adenomas. The Pituitary Study Group. Clinical Endocrinology 199849 441-445. (doi:10.1046/j.13652265.1998.00536.x)

24 Stochholm K, Gravholt $\mathrm{CH}$, Laursen T, Laurberg P, Andersen M, Kristensen LØ, Feldt-Rasmussen U, Christiansen JS, Frydenberg M \& Green A. Mortality and GH deficiency: a nationwide study. European Journal of Endocrinology 2007 157 9-18. (doi:10.1530/EJE-07-0013)

25 Erfurth EM, Bülow B, Mikoczy Z \& Hagmar L. Incidence of a second tumor in hypopituitary patients operated for pituitary tumors. Journal of Clinical Endocrinology and Metabolism 200186 659-662. (doi:10.1210/jc.86.2.659)

26 Chung TT, Drake WM, Evanson J, Walker D, Plowman PN, Chew SL, Grossman AB, Besser GM \& Monson JP. Tumour surveillance imaging in patients with extrapituitary tumours receiving growth hormone replacement. Clinical Endocrinology 200563 274-279. (doi:10.1111/ j.1365-2265.2005.02338.x)
27 Jostel A, Mukherjee A, Hulse PA \& Shalet SM. Adult growth hormone replacement therapy and neuroimaging surveillance in brain tumour survivors. Clinical Endocrinology 200562 698-705. (doi:10.1111/ j.1365-2265.2005.02282.x)

28 Karavitaki N, Warner JT, Marland A, Shine B, Ryan F, Arnold J, Turner HE \& Wass JA. GH replacement does not increase the risk of recurrence in patients with craniopharyngioma. Clinical Endocrinology 200664 556-560. (doi:10.1111/j.1365-2265.2006.02508.x)

29 Murray RD, Darzy KH, Gleeson HK \& Shalet SM. GH-deficient survivors of childhood cancer: GH replacement during adult life. Journal of Clinical Endocrinology and Metabolism 200287 129-135. (doi:10.1210/ jcem.87.1.8146)

30 Swerdlow AJ, Reddingius RE, Higgins CD, Spoudeas HA, Phipps K, Qiao Z, Ryder WD, Brada M, Hayward RD, Brook CG et al. Growth hormone treatment of children with brain tumors and risk of tumor recurrence. Journal of Clinical Endocrinology and Metabolism 200085 4444-4449. (doi:10.1210/jcem.85.12.7044)

31 Wilton P, Mattsson AF \& Darendeliler F. Growth hormone treatment in children is not associated with an increase in the incidence of cancer: experience from KIGS (Pfizer International Growth Database). Journal of Pediatrics 2010157 265-270. (doi:10.1016/j.jpeds.2010. 02.028)

32 Sklar CA, Mertens AC, Mitby P, Occhiogrosso G, Qin J, Heller G, Yasui Y \& Robison LL. Risk of disease recurrence and second neoplasms in survivors of childhood cancer treated with growth hormone: a report from the Childhood Cancer Survivor Study. Journal of Clinical Endocrinology and Metabolism 200287 3136-3141. (doi:10.1210/jcem.87.7.8606)

33 Ergun-Longmire B, Mertens AC, Mitby P, Qin J, Heller G, Shi W, Yasui Y, Robison LL \& Sklar CA. Growth hormone treatment and risk of second neoplasms in the childhood cancer survivor. Journal of Clinical Endocrinology and Metabolism 200691 3494-3498. (doi:10.1210/ jc.2006-0656)

34 Woodmansee WW, Zimmermann AG, Child CJ, Rong Q, Erfurth EM, Beck-Peccoz P, Blum WF, Robison LL \& GeNeSIS and HypoCCS International Advisory Boards . Incidence of second neoplasm in childhood cancer survivors treated with GH: an analysis of GeNeSIS and HypoCCS. European Journal of Endocrinology 2013168 565-573. (doi:10.1530/EJE-12-0967)

35 Patterson BC, Chen Y, Sklar CA, Neglia J, Yasui Y, Mertens A, Armstrong GT, Meadows A, Stovall M, Robison LL et al. Growth hormone exposure as a risk factor for the development of subsequent neoplasms of the central nervous system: a report from the Childhood Cancer Survivor Study. Journal of Clinical Endocrinology and Metabolism 201499 2030-2037. (doi:10.1210/jc.2013-4159)

36 Webb SM, Strasburger CJ, Mo D, Hartman ML, Melmed S, Jung H, Blum WF, Attanasio AF \& HypoCCS International Advisory Board. Changing patterns of the adult growth hormone deficiency diagnosis documented in a decade-long global surveillance database. Journal of Clinical Endocrinology and Metabolism 200994 392-399. (doi:10.1210/ jc.2008-0713)

37 Howlader N, Noone AM, Krapcho M, Garshell J, Neyman N, Altekruse SF, Kosary CL, Yu M, Ruhl J, Tatalovich Z et al. (Eds). SEER Cancer Statistics Review, 1975-2010. Bethesda, MD: National Cancer Institute. Based on November 2012 SEER data submission, posted to the SEER web site, April 2013. Accessed on 23 July 2013 at: http://seer.cancer.gov/csr/ 1975_2010/.

38 Ferlay J, Shin HR, Bray F, Forman D, Mathers C, Parkin DM \& GLOBOCAN 2008. Cancer Incidence and Mortality Worldwide: IARC CancerBase No. 10. Lyon, France: International Agency for Research on Cancer, 2010. Accessed on 23 July 2013 at: http://globocan.iarc.fr.

39 Breslow NE \& Day NE (Eds). Statistical Methods in Cancer Research. Volume II, - the Design and Analysis of Cohort Studies, vol 82, pp 65-69. IARC Scientific Publications: Lyon, France, 1987.

40 Perkins SM, Tu W, Underhill MG, Zhou XH \& Murray MD The use of propensity scores in pharmacoepidemiologic research. 
Pharmacoepidemiology and Drug Safety 20009 93-101. (doi:10.1002/ (SICI) 1099-1557(200003/04)9:2 <93::AID-PDS474>3.0.CO;2-I)

41 Rosenbaum PR \& Rubin DB. Reducing bias in observational studies using subclassification on propensity score. Journal of the American Statistical Association 198479 516-524. (doi:10.1080/01621459.1984. 10478078)

42 Shimatsu A, Tai S, Imori M, Ihara K, Taketsuna M, Funai J, Tanaka T, Teramoto A, Irie M \& Chihara K. Efficacy and safety of growth hormone replacement therapy in Japanese adults with growth hormone deficiency: a post-marketing observational study. Endocrine Journal 201360 1131-1144. (doi:10.1507/endocrj.EJ13-0083)

43 Caturegli P, Newschaffer C, Olivi A, Pomper MG, Burger PC \& Rose NR. Autoimmune hypophysitis. Endocrine Reviews 200526 599-614. (doi:10.1210/er.2004-0011)

44 Inskip PD, Ries LAG, Cohen RJ, Curtis RE. New malignancies following childhood cancer. In New Malignancies Among Cancer Survivors: SEER Cancer Registries, 1973-2000, pp 465-482. Eds RE Curtis, DM Freedman, E Ron, LAG Ries, DG Hacker, BK Edwards, MA Tucker \& JF Fraumeni Jr. Bethesda, MD: National Cancer Institute, NIH Publ. No., 05-5302, 2006.
45 Jenkins PJ, Mukherjee A \& Shalet SM. Does growth hormone cause cancer? Clinical Endocrinology 200664 115-121. (doi:10.1111/j.13652265.2005.02404.x)

46 Hatrick AG, Boghalo P, Bingham JB, Ayres AB, Sonksen PH, Russell-Jones DL \& Does GH. Does GH, replacement therapy in adult GH-deficient patients result in recurrence or increase in size of pituitary tumours? European Journal of Endocrinology 2002146 807-811. (doi:10.1530/eje.0.1460807)

47 Buchfelder M, Kann PH, Wüster C, Tuschy U, Saller B, Brabant G, Kleindienst A, Nomikos P \& German KIMS Board. Influence of GH substitution therapy in deficient adults on the recurrence rate of hormonally inactive pituitary adenomas: a case control study. European Journal of Endocrinology 2007157 149-156. (doi:10.1530/ EJE-07-0164)

48 Olsson DS, Buchfelder M, Wiendieck K, Kremenevskaja N, Bengtsson BÅ, Jakobsson KE, Jarfelt M, Johannsson G \& Nilsson AG. Tumour recurrence and enlargement in patients with craniopharyngioma with and without GH replacement therapy during more than 10 years of follow-up. European Journal of Endocrinology 2012166 1061-1068. (doi:10.1530/EJE-12-0077)

Received 17 December 2014

Revised version received 17 March 2015

Accepted 25 March 2015 